\title{
The Impact of War on Emergence of Depression and Posttraumatic Stress Disorder on Iranian Veterans of Iran-Iraq War
}

\author{
Aylar Mansouri \\ Alpen-Adria University of Klagenfurt, Department of Psychology , Starkfriedgasse 15, Vienna, Austria
}

\begin{abstract}
Iran has been involved in many wars throughout its ancient history, a vivid example is the Iran-Iraq war. This imposed war was ongoing during September 1980 - August 1988 (Mohsenian, 2008). ). The main goal of this study was to investigate differences depression and PTSD symptoms in veterans who participated in the IranIraq compared to community sample. The objectives of this research were: 1.Comparing depression in soldiers who are PTSD patients and ordinary people. 2. Comparing PTSD symptoms in soldiers and ordinary people. The research hypotheses were formulated according to the defined objectives. The statistical population included the Iran-Iraq war veterans and the ordinary male individuals within the age range of 25-50 residing in Tehran. . The data analysis for present research was down descriptively. The Foundation of Martyrs and Veterans' Affairs of the city of Tehran permitted the researcher to select the statistical samples through the families of martyrs and veterans in person. The related questionnaires were handed in to the testees in person. The research objectives and nondisclosure of information were explained to the testees prior to distribution of the questionnaire. The data was collected using a PTSD checklist by Weathers, Litz, Herman, Huska, Kean etal (1993) and the Beck depression inventory. The multivariate effect indicates a significant difference between the depression and PTSD in war veterans and ordinary individuals aged 25-50. Depression and PTSD in Iran-Iraq war veterans it was higher compared to ordinary individuals.
\end{abstract}

Keywords: Veterans, PTSD, Depression

\section{Introduction}

Iran has been involved in many wars throughout its ancient history and Iranians have been Subject to the results of war damage. A vivid example which readily comes to mind is the Iran-Iraq War. This imposed war was ongoing during September 1980 - August 1988 (Mohsenian, 2008).Great wars and their many victims did not bring about peace and mental security for humanity, rather they led to mental hospitals being full of patients whose number increased every day as more and more war veterans were being diagnosed with mental illnesses and disorders. In other words, one cannot ignore the direct and indirect outcomes of war on society although it has for long been over. Some of the negative outcomes of this war include many war veterans becoming martyred with so many getting wounded in action; To name some of the negative effects of war veterans, one can make mention of Post-traumatic Stress Disorder and the resultant depression in war veterans.

\section{Statement of the Problem}

Post-traumatic Stress Disorder (PTSD) is a psychiatric disorder caused by traumatic events Such as wars. This illness is considered to be a chronic anxiety disorder caused in response to one or more pathogenic stimuli. The disorder can be diagnosed as a result of re-experiencing symptoms and avoidance or emotional numbing and increased arousal which can cause significant clinical stress or performance disorder (Beck and Clark, 2010).

As stated in the fifth edition of the Diagnostic and Statistical Manual of Mental Disorders (American Psychiatric Association, 2013), PTSD is classified under anxiety disorders and is known as a post-traumatic stress disorder. In this type of disorder, illness symptoms occur as a result of atraumatic event and normally go beyond the tolerance of human being. The stimuli causing this syndrome lead to restlessness symptoms. 
Mental traumatic events which may cause this syndrome include: war, flood, earthquake, car Accidents, bombardment, terror or living in concentration camps the possible reactions of the patient to these events include: excessive fear, helplessness or fright. Therefore, the individual constantly avoids facing the stimuli which are somehow related to the damage. The individual usually makes a conscious effort to refrain from the thoughts, feelings or conversations about damaging events as well as activities, situations or individuals who bring back memories of that event. This act of avoidance may include any of the following: amnesia when it comes to an important aspect of the damaging event, a substantial decrease in participation in important activities, a lethargic feeling or hatred towards other people, limited scope of emotions, and a feeling that death is proximate. All of these symptoms are similar to the symptoms of depression. In line with this, some scholars have pointed out the similarities between PTSD and two other psychiatric disorders, i.e. major depressive disorder and panic disorder (ibid).

\section{Review of Empirical Literature (research background)}

PTSD is one of the very few psychiatric disorders defined based on causes. In fact, the this Disorder is not caused unless a stressor $\left(\right.$ harm $\left.^{*}\right)$ is at work. Nonetheless, harmful event does not Suffice for diagnosis and many people who undergo stress, do not develop a disorder. Most probably, there is an interaction between the event and the victim. PTSD symptoms are affected by the degree of significance the victim attaches to the stressor. That is, how fearful the stressor seems to the victim truly matters. There is no direct relationship between severity of the stressor and PTSD symptoms. Those individuals are more prone to developing PTSD who feel nobody supports them or are featured with timidity, shyness, or feeling of guilt. PTSD has to be studied by taking some factors into consideration such as: biological condition, psychological and social factors prior to the harm, the specifications of the stressor, the time and place of the event, situational factors, personal features and the post-trauma conditions. Furthermore, the mental significance of the stressor is also of importance. The survivors of a traumatic event may feel guilty and PTSD can make them prone to depression or even augment stress (Ya'qubi, 2011).

According to the results of a research conducted by Shafiee Kamalabadi et al. (2014), titled "An investigation into PTSD and its coexistence with Personality Disorder among war veterans in Tehran", $39 \%$ percent of war veterans suffer from PTSD. If the wounded in action suffer from partial disability of less than $25 \%$ and his/her university degree is higher than Bachelor's degree, Then they are less likely to be afflicted with this disorder. The Borderline Personality Disorder is Recognized as the most common personality disorder accompanied with PTSD among the war Veterans (who also suffer from PTSD); i.e. some 17/9\% of the war veterans who suffer from PTSD also suffer from Borderline Personality Disorder while $4.8 \%$ of those who have not been diagnosed with PTSD suffer from Borderline Personality Disorder. The frequency of Avoidant Personality Disorder was $10 \%$ as compared to $2 \%$. Nonetheless, depression had not been studied in their research.

Another study by Zargar et al. (2011) titled "an investigation into mental health of Iranian War veterans: 30 years later" found that nearly $50 \%$ of the former war veterans suffer today from Mental disorders such as depression, anxiety, obsession (OCD), aggressive behavior, phobia, Psychosis and other mental disorders. However, the study does not specifically refer to PTSD.

Mohammadkhani et al. (2007) conducted a research on symptoms of PTSD and resultant depression, anxiety, anger and Dissociative Identity Disorder (DID) based on sexual segregation of two groups of male and female adolescents who were victims of Bam earthquake compared them to normal Tehrani adolescents. The findings indicate that more symptoms associated with depression, anxiety, anger and DID can be seen in the group of adolescents who have experienced traumatic events as compared to normal adolescents. As for the group diagnosed with PTSD, the female population. reportedly indicated all the symptoms of PTSD (except for anger)on a higher level compared to the male population; However, when PTSD symptoms (those truly symptomatic of illness, not based on the mean of all the points) were studied for both genders, it was revealed that the male population reportedly revealed more symptoms compared to the female population. Although the difference was not significant, at least it showed that girls do not become diagnosed with PTSD any more than boys. In fact, the factor that causes frequency of PTSD symptoms in girls to be more compared to boys is pertinent to dominant patterns of sexual roles. Nonetheless, the frequency of PTSD in the test group was $20 \%$. According to the available literature, no research has to date studies both PTSD and depression in Iran-Iraq war veterans. Therefore, the significance of the proposed research is justified.

\section{Theoretical review of literature}


Depression is a natural response to the pressures of life stemming from internal conflicts or in reaction to an external factor. Depression is an illness which causes changes in mood, behavior, thoughts, perceptions, and physiological performance; It is considered to be abnormal and is recognized as a disorder when its severity does not match the causing event. Different studies show that minor mood swings are on the same continuum just like more severe disorders; i.e. the difference lies in severity rather than the type. These results have been acknowledged in other large scale research related to this issue. Nonetheless, these mood disorders differ in their revealing symptoms. Thus, unipolar and bipolar disorders have different micro-types While the causal factors and treatment of these micro-types is somewhat different. In fact, periods of depression are obviously the most common grounding reason leading to suicide (James et al., 2010).

Sadness, despondency and hopelessness about future are familiar feelings for most people. When we feel depressed, we also feel unhappy. However, the feeling normally wears off soon and after a few days/weeks or once it reaches a certain level of severity, it automatically wears off. In fact, mild and short-term depression may be natural and adaptable in the long run. It so appears that depression is mainly a result of facing fearful limiting thoughts and feelings the individual usually avoids. It is usually expected to see normal depression in people who experience unpleasant events such as interpersonal problems or financial failures (James et al., 2010).

Depression is an illness with mood swings as its primary and main feature; it includes a range of feelings from sadness caused by a mild hopelessness to severe frustration (fluctuations are possible). This noticeable change in behavior causes altered viewpoints, insights, thoughts, opinions and physiological performance. Depression may exist as a symptom of many mental or physical illnesses and function as a secondary part on a clinical manifestation. Depression can also be a natural feeling indicative of helplessness. Depression affects the entire body organism; it also affects all aspects of individual's life. The main symptom of depression is feeling uninterested about commonly enjoyable daily activities such as socializing, doing sports or leisure activities and eating food. All in all, depression depends on its symptoms and their gravity. In cases of mild depressions, a few symptoms are present. The most important symptom is failure to gain pleasure from things which used to be pleasurable for the individual before. Food loses its taste, sexual activity loses its appeal, working becomes boring, and the once significant socializing activities become meaningless (Moosavi et al., 2007). Normal types of depressions are almost always caused by stress. Two relatively common symptoms of depression are taken into account here: symptoms which are not normally considered mood disorders, except for the cases where they become abnormally severe or lengthy (Hashemi, 2011).

However, clinical depression (where the individual does not feel pleasure but experiences hopelessness) has other symptoms as follows: helplessness, reduced self-esteem, thought distraction, masochism, complaining about pain, breathing problems, digestive problems, headaches and physical problems. Other distinctive symptoms include: loss of appetite, loss of weight, insomnia, fear, and sleeping disorders (e.g. waking up early), reduced energy, fatigue, lack of attention to daily chores and loss of interest in sex, feeling guilty, suicidal thoughts and masochism. To sum up, depressed people mention that their brains are faulty. They fear that they may lose their senses or control over their feelings (Diagnostic and Statistical Manual of Mental Disorders, 2013).

Although there seems to be an obvious cause and effect relation between a stressful event and emergence of disorder, it is impossible to explain emergence of disorders like depression, Anxiety and PTSD. Although any trauma could affect individuals to different extents, such disorders are caused in few people. Researchers state three factors in their attempt to explain the causes of such disorders in some individuals: childhood experiences, personality type, and social support (Alipoor, 2007).

In addition, any type of disability can function as a source of mental pressure leading to depression. Obviously, a disabled family member with chronic disabilities can impact the family unity and bring about further mental and sociological disorders (Islaminasab, 2013). The most recent widespread cognitive results from research about simultaneous occurrence of a number of disorders indicate that prevalence of Major Depressive Disorder (MDD) also known as unipolar depression is $17 \%$ (the rate of 12 month prevalence is almost $7 \%$ ) in a lifetime span (Roussis and Wells, 2006). Furthermore, the rate of unipolar depression is by far higher in women (almost 2 to 1 ) as is the case with most anxiety disorders (James et al, 2010). Thus, emphasis on diagnosing different disorders and providing opportunities for learning about simultaneous occurrence of disorders can lead to changes to the external layers from a clinical perspective (clinic/practice). Nonetheless, the question remains: Are depression and PTSD different in those Iranian war veterans who have been diagnosed with PTSD? The proposed study is meant to answer this question 


\section{5 .Depression}

Depression is used to refer to a special state of feeling, reaction in a given situation and a behaviour style particular to a given individual. The feeling of depression is normally known as sadness or melancholy, likely to occur in a rainy cold weather or after quarrelling with a friend. A situation which is expected to be delightful, most often puts an end to such feeling. People get this feeling most often after Christmas holiday, moving to a new house or birth of a newborn (Sarason and Sarason, 2011).

\subsection{Prevalence of depression}

Depression is one of the most common, detrimental and high-cost types of mental trauma (Luppa et al., 2007). Some $2025 \%$ of women and $1017 \%$ of men undergo depression within the course of their lifetime (Levinson, 2006).

As a matter of fact, depression affects one in every five individual while women are two to Three times more likely to succumb to depression in comparison to men (Sloan \& Kornstein, 2003; Calvete, 2010). This type of disorder is very likely to affect the patient all over again. In addition, there is a high risk that one period of depression would be followed by other fits. Some $15 \%$ of individuals suffering from severe depression try to commit suicide (Kessler, 2002). According to the World Health Organization, depression will be the second leading type of illness to debilitate the world to the effect that some 121 million individuals would fall into it (WHO, 2010, as quoted by Berry and York, 2011).

As a matter of fact, depression affects one in every five individual while women are two to Three times more likely to succumb to depression in comparison to men (Sloan \& Kornstein, 2003; Calvete, 2010). This type of disorder is very likely to affect the patient all over again. In addition, there is a high risk that one period of depression would be followed by other fits. Some $15 \%$ of individuals suffering from severe depression try to commit suicide (Kessler, 2002). According to the World Health Organization, depression will be the second leading type of illness to debilitate the world to the effect that some 121 million individuals would fall into it (WHO, 2010, as quoted by Berry and York, 2011).

\subsection{Depression signs and symptoms}

Depression signs come in four different groups. In addition to the physical symptoms, physical, motivational and cognitive symptoms ought to be mentioned as well. An individual must not necessarily indicate all of these symptoms to be diagnosed with depression. Nevertheless, the more symptoms an individual presents and the more acute the symptoms reported in a constellation, the more accurate the diagnosis (Seligman and Rosenhan, 2012)

\subsubsection{Mood Symptoms}

Grief is the most frequent and apparent emotional symptom in depression. Such depressive feeling is most often associated with anxiety. Most depressed individuals suffer from anxiety as well. However, depression is not a prerequisite of depression (Barlow, 2009). Absence of the feelings of satisfaction and happiness are almost as prevalent as the feeling of sadness (sorrow/melancholy) in depression.

Those activities which used to bring about the feeling of satisfaction and content become Monotonous and boring. At the initial stages, the individual experiences lack of interest in merely a couple of activities.

\subsubsection{Cognitive symptoms}

The depressed individual has a negative attitude about him/herself. These negative beliefs and attitudes undermine the individual's feelings about him/herself and his/her future. A depressed individual has a low self esteem not to mention that $\mathrm{s} /$ he berates him/herself for his/her problems and feels guilty.

The individual feels responsible for his/her failure. Even Though the failure may not be definite, such individuals believe that it is apparent and s/he is the main reason for such failure (Seligman and Rosenhan, 2012). In addition to the negative feelings and the feeling of guilt, the depressed individual almost always thinks about a hopeless future mingled with pessimism. Such thoughts will result in ruining the interpersonal relations (Johnson \& Jacob, 2009).

\subsubsection{Motivational symptoms}

Depressed individuals have serious problems in waking up every morning, going to work, starting a project and keeping themselves busy. Ambivalence and uncertainty in decision making are among the most common symptoms of 
depression. Decision making can be a paralyzing fear for the depressed individual. In cases of severe depression, the patient is unable to make decisions. Such state is known as "Paralysis of Will".

\subsubsection{Somatic symptoms}

In cases of major depression, all the biological and mental pleasures which add value to life fade away. Loss of appetite is very common between depressed individuals. In cases of severe or moderate depression, the individual loses weight while in cases of mild depression gaining weight is likely to occur as well. Sleep disorder is very common as well.

Depressed individuals are likely to experience many difficulties in falling asleep. Sleep disorder and weight loss lead to weakness and fatigue. The depressed individual may also lose his/her sexual desire. A great percentage of people who are diagnosed with depression also present somatic symptoms (Seligman \& Rosenhan, 2012). Depressed individuals are more vulnerable to Physical illnesses since severe depression can debilitate the individual physically. Depression is most often one of the primary symptoms of infectious diseases, cancer and heart disease (Carney, Freedland \& Jaffe, 1990).

\subsection{Depression cycles' diagnostic criteria based on DSM-IV-TR}

A-In the event that five or more of the following symptoms exist in a cycle of fortnight and indicate change compared to the previous level of performance; at least one of the symptoms is revealed as a 1) depressed mood or 2) loss of interest and feeling pleasure.

It is noteworthy that those symptoms which are indicative of a general medical disorder or the delusions and illusions inconsistent with mood must not be taken into account in this case.

Depressed mood most of the day according to the mental records or others' observations. It is noteworthy that in case of children and adolescents, it could be revealed as irritability.

Significant decrease in feeling joy and interest in all or almost all of the activities related to the major part of the day.

Significant decrease in weight without exerting control or being on diet; Increased weight or increase/decrease in appetite (Note that in case of children, one should beware of Increase below the expected.

Insomnia or hypersomnia on an almost daily basis

Mental stimulation or mental slowness on an almost daily basis

Fatigue or exhaustion on an almost daily basis

Baseless feeling of worthlessness and guilt

Reduced concentration and thinking abilities on an almost daily basis

Repetitive thoughts of death

B- The symptoms do not include criteria related to a mixed cycle

C-Symptoms related to significant clinical sadness disturbed social activity, professional Performance or other aspects

D- The symptoms do not stem from the physiological impact of a given substance or a general medical disorder

E-) Bereavement does not further explain the symptoms; i.e., after loss of a beloved one, the symptoms continue for more than two months and result in obvious performance impairment and obsession with feeling of worthlessness or slow mental and physical activity (Sadock and Sadock, 2005).

\section{6 .Posttraumatic stress disorder (PTSD)}

The history of posttraumatic stress disorder, reveals the long history and diversity of this

Disorder. Until 1980, this disorder was not officially considered to be a disorder under the Diagnostic and Statistical Manual of Mental Disorders published by American Psychiatric (April \& Beck, 2000). However, during the American civil war, cardiac symptoms related to autonomic nervous system similar to what is called PTSD today, was seen among 
soldiers fighting in the war and it was called the soldier's heart. Da Costa published an article in 1871, entitled "On irritable heart; a clinical study of a form of functional cardiac disorder and its consequences" describing this state of the soldiers. The main reason for this appellation (traumatic neurosis) was the influence of psychotherapists in 19001909 especially in the United States. Frederick Mort, the English pathologist, called the disorder traumatic psychological reactions. In his opinion, such reactions related to brain lesions were caused as a result of explosion. In the Second World War, traumatic reaction to war led to development of different names and classifications such as operational fatigue and traumatic neurosis. Finally, the psychiatric side effects on soldiers after the Vietnam War lead to creation of the concept of posttraumatic stress disorder (PTSD). The disorder has still the same name today (Sadock and Sadock, 2007).

Symptoms of the wounded in action and the Iran-Iraq war: during the Iran-Iraq war, the ideological beliefs about war and the dominant sociocultural context impeded the veterans from expressing their feelings and concerns, especially those related to neurotic and psychological problems. Iran Mohajer was the first to publish an article in 1986 as the war was ongoing to discuss and emphasize neuroticism among Iranian combatants. After the war, several studies were carried out about the combatants, prisoners and victims of war. The expert attention was drawn to various symptoms about which chronic victims of war complained throughout years. However, these vague complaints were not resolved easily. Observations indicated that posttraumatic stress disorder symptoms like reexperiencing and avoidance was lower than expected in many of these wounded in action. Many of the wounded showed specific signs and symptoms due to injuries caused by blast waves and chemical weapons. An investigation into symptoms of those wounded in Iranlraq war gave rise to the soldier's heart syndrome. The symptoms related to this syndrome are emotional, e.g. outrage, reduced tolerance of acoustic stimuli, despair and depression, behavioural and social symptoms such as family conflict, work related problems, drug overdose, and physical symptoms such as sleep disorder, headaches, decreased libido or impotence, respectively (Mohajer, 1986; Momtazi, 2001).

\section{Research Objectives}

\subsection{General objectives}

The general objective of the present research is to study the impact of war on depression and PTSD development in Iranian male war veterans through comparison of the war veterans with Normal individuals. It is expected that the results of this study (e.g. depression and PTSD rates) could contribute to alleviation of depression and PTSD symptoms and also to solution of the related difficulties as far as the affected war veterans are concerned.

\subsection{Specific Objectives}

Comparison of depression in the war veterans suffering from PTSD and normal people Comparison of PTSD symptoms in war veterans and normal people.

\section{Methodology}

This research is descriptive with an ex-post facto design where PTSD and depression are Compared in Iran-Iraq war veterans and normal people. The research data is collected using field method and questionnaires. Furthermore, the data collection and theoretical framework design processes are carried out based on secondary research where reference is made to previously conducted available literature.

\subsection{Statistical population, Sample, Sampling Method}

The statistical population of the proposed research is made up of those war veterans diagnosed with PTSD who reside in Tehran. The sampling method used is purposive sampling. The qualification required to be included in the research sample is having PTSD and being male. Given the number of variables in the study (Depression and PTSD) and taking the table designed by Krejcie and Morgan (1970) into consideration, the sample size required for this study will be 100 .

\subsection{Research Tools}

\subsubsection{Beck's Depressive Inventory II (BDIII) questionnaire}

This questionnaire is one of the research tools meant to be used in this research. This questionnaire includes 21 items which measure physical, behavioural and cognitive symptoms of depression. Each item lists four statements on a four- 
point scale (from 0 to 3 ) based on increasing intensity. A value of 03 is given to each answer to the test. Afterwards, the total score is compared to a key to determine the severity of depression. The cutoff scores used to measure depression severity range between 063 and determine different levels of depression from mild to severe. The 21 items of this questionnaire include: Sadness, Pessimism, Past failure, Loss of pleasure, Guilty feelings, Punishment feelings, Selfdislike, Self-criticalness, Suicidal thoughts or wishes, Crying, Agitation, Loss of interest, Indecisiveness, Worthlessness, Loss of energy, Changes in sleeping pattern, Irritability, Changes in appetite, Concentration difficulty, Tiredness or fatigue, Loss of interest in sex. The general results of the depression test can be interpreted based on the BDIII cutoffs. None of the cutoffs explains absence of depression. This questionnaire is designed for individuals aged 13 and over.

\subsubsection{PTSD checklist:}

The PTSD checklist (Weathers, Litz, Herman, Huska, Kean et al., 1993) was developed for the National Center for PTSD in the United States. The checklist includes 17 items 5 of which are pertinent to the signs and symptoms of reexperiencing the traumatic event, 7 items are related to signs and symptoms of avoidance and emotional numbing, and 5 other items of the checklist are related to the signs and symptoms of increased arousal. The checklist is scored as follows:

Summation of all the scores gained from answering to each of the 17 questions based on a five point Likert scale (with 1 $=$ not at all, $2=$ a little bit, $3=$ moderately, $4=$ quite a bit, $5=$ extremely). The total score can range between 1785 . The cutoff for military forces is determined to be 50 and only reliable in their case.

\subsection{Research Hypotheses}

1-War impacts outbreak of depression and PTSD in Iran-Iraq war veterans.

2-War impacts outbreak of depression in Iran-Iraq war veterans.

3-War impacts outbreak of PTSD in Iran-Iraq war veterans.

\subsection{Research Procedure}

The related permit was obtained from the Foundation of Martyrs and Veterans' Affairs of the city of Tehran to select the statistical sample by going to the families of martyrs and veterans in person. The related questionnaires were handed in to the testees in person. The details about the research objectives and nondisclosure of information were explained to the testees prior to distribution of the questionnaire. The testees were afterwards asked to answer all the questions carefully.

\subsection{Data Analysis Method}

The data in question includes the scores obtained by each participant on the general depression and PTSD scales. To analyze the data and report the results, descriptive statistics indices (mean, standard deviation, minimum score, maximum score, range, skewness, kurtosis) and inferential statistics (t-Test for independent groups and multivariate analysis of variance) will be used. In addition, variance analysis will be used for simultaneous comparison of the research variables.

\subsection{Information Analysis Method}

The information analysis in the current study is done using the t-Test for independent groups. In addition, variance analysis will be used for simultaneous comparison of the research variables.

\section{Research questions and Interpretation of result}

The present study was mainly conducted to answer the following question:

Does war impact outbreak of depression and PTSD in Iran-Iraq war veterans?

Given that the main research question is an investigation into the impacts of war and how it has possibly resulted in outbreak of depression and PTSD in Iran-Iraq war veterans and also considering the fact that many studies confirm there is a correlation between the mentioned variables, this section includes information related to assessment of the intercorrelation of variables (depression and PTSD) based on the studies sample. 
The related results have been included in Table 1.

Table1.

Correlation Matrix of Variables Related to Level of Education

(Depression and PTSD)

\begin{tabular}{lll}
\hline Variables & Depression & PTSD \\
\hline Depression & 1 & \\
PTSD & $0.89^{* *}$ & 1
\end{tabular}

${ }^{* *}$ sig<0.01 *sig<0.05n=765

As detailed in Table 1, depression and PTSD have meaningful intercorrelation. Given the intercorrelation of these two dependent variables (depression and PTSD) and with respect to the fact that the main research question was meant to make a comparison between the Iran-Iraq war veterans and ordinary individuals aged 25-50 residing in Tehran, multivariate analysis of variance (MANOVA) was used for statistical analysis of the variables.

\section{Table 2}

MANOVA Results on Depression and PTSD in War Veterans and Ordinary Individuals

\begin{tabular}{lllllll}
\hline $\begin{array}{l}\text { Change } \\
\text { sources }\end{array}$ & $\begin{array}{l}\text { Wilk's } \\
\text { Lambda }\end{array}$ & $F$ & $\begin{array}{l}\text { Degree of } \\
\text { freedom }\end{array}$ & $\begin{array}{l}\text { Degrees of } \\
\text { freedom } \\
\text { error }\end{array}$ & Significance & $\begin{array}{l}\text { Effect } \\
\text { size } \\
(\%)\end{array}$ \\
\hline Group & 0.89 & 47.22 & 2 & 762 & 0.0001 & 0.11 \\
\hline
\end{tabular}

Table .2 indicates the results of multivariate analysis of variance test results of depression and PTSD in two groups: war veterans and ordinary individuals within the age range of 2550. As detailed in Table 2 the results are indicative of a significant multivariate effect for "Group". This multivariate effect confirms that war affects outbreak of depression and PTSD and there is significant difference between the war veterans and ordinary individuals within the age range of 25-50 (Wilk's Lambda result $=0.89$ and $F C=47.22$ and $P<0.000$ ).

Independent tTest were conducted for each group, i.e. war veterans and ordinary individuals considering dependent variables in order to test the subhypotheses of the study as follows:

Does war impact outbreak of depression in Iran-Iraq war veterans?

To study the impact of war on outbreak of depression, a comparison was made between the means resultant from depression in Iranlraq war veterans vs. ordinary individuals with both groups being within the age range of 25-50 and residing in Tehran. The comparison was made using t-Test for independent groups as detailed in T able 3

\section{Table 3}

T-Test Results Comparing Depression in War Veterans vs. Ordinary Individuals within the Age Range of 25-50

\begin{tabular}{|c|c|c|c|c|c|c|c|}
\hline \multirow{2}{*}{$\begin{array}{l}\text { Variable } \\
\begin{array}{l}\text { Homogeneity of } \\
\text { variances }\end{array}\end{array}$} & \multicolumn{2}{|c|}{ Iran-Iraq war veterans } & \multicolumn{2}{|c|}{$\begin{array}{l}\text { Ordinary people aged } \\
25-50\end{array}$} & \multirow[t]{2}{*}{ df } & \multirow[t]{2}{*}{$t$} & \multirow[t]{2}{*}{ sig } \\
\hline & Mean & $\begin{array}{l}\text { Standard } \\
\text { deviation }\end{array}$ & Mean & $\begin{array}{l}\text { Standard } \\
\text { deviation }\end{array}$ & & & \\
\hline & 25.39 & 10.53 & 19.04 & 10.13 & 763 & 8.50 & 0.0001 \\
\hline Heteroscedasticity & & & & & 760.99 & 8.50 & 0.0001 \\
\hline
\end{tabular}

At first Levene's test for equality of variances was conducted. The test results indicated that variances of the two groups differed with one another on a general scale since the significance was more than 0.05 . Therefore, the null hypothesis 
$(\mathrm{H} 0)$, which states that the variances are equal, was confirmed. Accordingly, t-statistic was used for homogeneous variances and the calculated $t$ was 8.50 and significant in this sense (sig<0.01). Therefore, the depression mean is higher in Iran-Iraq war veterans in comparison to ordinary individuals (with both groups within the age range of 2550 and residing in Tehran). Thus, war impacts the development and outbreak of depression.

At first Levene's test for equality of variances was conducted. The test results indicated that variances of the two groups differed with one another on a general scale since the significance was more than 0.05 . Therefore, the null hypothesis $(\mathrm{HO})$, which states that the variances are equal, was confirmed. Accordingly, t-statistic was used for homogeneous variances and the calculated $t$ was 8.50 and significant in this sense (sig<0.01). Therefore, the depression mean is higher in Iran-Iraq war veterans in comparison to ordinary individuals (with both groups within the age range of 2550 and residing in Tehran). Thus, war impacts the development and outbreak of depression.

The next sub-hypothesis was as follows:

\section{Does war impact outbreak of PTSD in Iran-Iraq war veterans?}

To study the impact of war on outbreak of PTSD, a comparison was made between the means resultant from PTSD in Iranlraq war veterans vs. ordinary individuals with both groups being within the age range of 2550 and residing in Tehran. The comparison was made using tTest

For independent groups as detailed in T able .4 .

\section{Table 4}

T-Test

Results Comparing PTSD in War Veterans vs. Ordinary Individuals Within the Age Range of 25-50

\begin{tabular}{|c|c|c|c|c|c|c|c|}
\hline Variable & \multirow{2}{*}{$\begin{array}{l}\text { Iran-Iraq } \\
\text { war } \\
\text { veterans }\end{array}$} & & \multirow{2}{*}{\multicolumn{2}{|c|}{$\begin{array}{l}\text { Ordinary people aged } \\
25-50\end{array}$}} & \multirow[t]{2}{*}{ df } & \multirow[t]{2}{*}{$t$} & \multirow[t]{2}{*}{ sig } \\
\hline \multirow{2}{*}{$\begin{array}{l}\text { Homogeneity of } \\
\text { variances }\end{array}$} & & & & & & & \\
\hline & Mean & $\begin{array}{l}\text { Standard } \\
\text { deviation }\end{array}$ & Mean & $\begin{array}{l}\text { Standard } \\
\text { deviation }\end{array}$ & 763 & 9.71 & 0.0001 \\
\hline Heteroscedasticity & 47.73 & 15.43 & 37.98 & 12.13 & 718.53 & 9.72 & 0.0001 \\
\hline
\end{tabular}

At first Levene's test for equality of variances was conducted. The test results indicated that variances of the two groups differed with one another on a general scale since the significance was less than 0.05 . Therefore, the null hypothesis $(\mathrm{H} 0$ ), which states that the variances are equal, was not confirmed. Accordingly, t-statistic was used for heterogeneous variances; The calculated $t$ was 9.71 and significant in this sense (sig<0.01). Therefore, the PTSD mean is higher in IranIraq war veterans in comparison to ordinary individuals (with both groups within the age range of 2550 and residing in Tehran). Thus, war impacts the development and outbreak of depression.

\section{References}

[1] Akbari, Gh. (2006). Youth and adolescence difficulties (2nd Ed.). Tehran: Savalan Publications.

[2] Alipour, I. (2006). PTSD symptoms in the wounded in action: Iran- Iraq war. Tehran: Foundation of Martyrs and Veterans Affairs'

[3] Medical-Engineering Research Center.

[4] American Psychological Association (2000). Diagnostic and statistical manual of mental disorders (text rev., M. Nikkhah and H. Avadis Yans, Trans). Tehran:

[5] Sokhan Publications.

[6] American Psychological Association (2013). Diagnostic and statistical manual of mental disorders (5th Ed., A. Shamlou et al., Trans). Tehran: Shams

[7] Publications.

[8] American Psychiatric Association Diagnostic and Statistical Manual of Mental Disorders. 5th ed. Washington. (2013). DC: Am Psychiatric Association.

[9] Association, A. P. and A. P. Association (2000). Diagnostic and statistical manual-text revision (DSMIVTRim, 2000), American Psychiatric Association. 
[10] AubertKhalfa, S., et al. (2008). "Evidence of a decrease in heart rate and skin conductance responses in PTSD patients after a single EMDR session."

[11] Journal of EMDR practice and research 2(1): 5156.

[12] Averill, P. M. and J. G. Beck (2000). "Posttraumatic stress disorder in older adults: a conceptual review." Journal of Anxiety disorders 14(2): 133156.

[13] Azad, H. (2003). Psychopathology (1). Tehran: Besat publications.

[14] Barker, D.g., Mendenhall, C.L. Simbal,L.A \& et al (1997). relationship post-traumatic stress disorder and selfreported

[15] physical systems persian gulf war veterans.

[16] Barlow, D .H. (2009). Anxiety and its disorders: The nature and treatment of anxiety and panic (2nd Ed.).New York: Guilford Press.

[17] Beck, A., Amerie, G., Routh, L. and Berg, G. (2000). Cognitive model of anxiety (A. Pasalari Behjani, Trans). Tehran: Young Scientists Publications.

[18] Beck, A. T. \& Clark, D. A. (2010). Cognitive Therapy of Anxiety Disorders Science and Practice. THE GUILFORD PRESS. New York, NY 10012

[19] Beck, A. T. (1976). Cognitive therapy and the emotional disorders. New York: International Universities Press.

[20] Beck, A. T. (2006). How an anomalous finding led to a new system of psychotherapy.

[21] Beck, A.T., Rush, A. J., Shaw, B. F.,\& Emery,G. (1979). Cognitive therapy of depression. New York :Guilford press.

[22] Billings, A. G., et al. (1983). "Socialenvironmental factors in unipolar depression: comparisons of depressed patients and non-depressed

[23] controls." Journal of abnormal psychology 92(2): 119.

[24] Carney, R., Freedland, K., \& Jaffe, A. (1990). Insomnia and depression prior to myocardial infarction. Psychosomatic Medicine, 52, 603609

[25] Clark, D. A., Beck, A.T., \& Beck, J. S. (1994). Symptom differences in major depression, dysthymia, panic disorder, and generalized anxiety disorder. American

[26] Journal of Psychiatry,151(2), 205209H.

[27] Compas, B. E. (1987). "Coping with stress during childhood and adolescence." Psychological bulletin 101(3): 393.

[28] Davison, G. C., et al. (2004). Abnormal Psychology, with Cases , Wiley.

[29] Davidian, H. (2006). Depression and its treatment based on an Iranian cultural perspective (1st Ed.). Tehran: Academy of Medical Sciences Islamic Republic of

[30] Iran.

[31] Dekel R, Enoch G, Solomon Z. The contribution of captivity and PostTraumatic Stress Disorder to marital adjustment of Israeli couples. Journal of Social and

[32] Personal Relationships. 2008;3: 497510.

[33] Dezhkam, M. and Aminolroaya, A. (2003). A comparison of mental health levels in spouses of Tehrani wounded in action patients admitted to Sadr Hospital and

[34] and Imam Hussein Hospital, respectively. First Conference on Family and the Wounded in Action Medical Science and Engineering Research Center of

[35] the Wounded in Action, Veterans Affairs OrganizationDepartment of Cultural Affairs and Sports. Retrieved from

[36] http://www.civilica.com/PaperCVTF01CVTF01_011.html.

[37] Elahi, A. (1994). Ethnic psychodrama. Tehran: Iran University of Medical Sciences.

[38] Eslaminasab, A. (2013). Psychology of the disabled and the wounded in action. Tehran: Safi Ali Shah Publications.

[39] Esmaeili, L., Pour Abaeian Isfahani, M.H., and Dabbashi, F. (2015). How music therapy affects depression in chronic PTSD patients. The Wounded in Action Medicine Quarterly, 7(2), 7482.

[40] Evans, M.D., Hollon, S.D., DeRubeis, R.J., Piasecki, J.M. (1992). Differential relapse following cognitive therapy and pharmacotherapy for depression. Archives

[41] of General Psychiatry, 49(10), 802808.

[42] Fairbank, J. A. and R. A. Nicholson (1987). "Theoretical and empirical issues in the treatment of post-traumatic stress disorder in Vietnam veterans." Journal of

[43] Clinical Psychology 43(1): 4455.

[44] Fakhri, F., Aghaei, H., and Khajeh Hosseini, H. (2005). An investigation into effectiveness of psychodrama on improvement of interactive skills of children aged

[45] 1015. Rehabilitation, 6(2), 2428.

[46] Friedman, M. J. (2006). "Posttraumatic stress disorder among military returnees from Afghanistan and Iraq." American Journal of Psychiatry .

[47] Gharayi, B., Asgharnejad Farid, A., Yazdandoost, R., Dadashzadeh, H. (2003). Effectiveness of Cognitive Behavioral Group Therapy and Exposure Therapy

[48] on Interpretation Bias and Fear of NEgative Evaluation in Social Anxiety Disorder. Iranian Journal of Psychiatry and Clinical Psychology, , 18 (1),

[49] 4051 
[50] Ghasemzadeh, K. (2008). An investigation into the management style conflicting with job satisfaction levels of the teaching staff in Mazandaran schools for the

[51] mentally challenged students: Rehabilitation Management (master's thesis). Tehran: University of Social Welfare and Rehabilitation Sciences.

[52] Ghorashi Zadeh, M.A. (2007). PTSD and bipolar disorder: co-occurring disorders. Abstracts from the 4th Symposium on Nervous and Mental Problems Resultant

[53] from War (27). Veterans Medical and Engineering Research Center: Tehran, Iran.

[54] Goudarzi, M.A. (2003). Investigating the Validity and Reliability of Beck's Hopelessness in a Group of University Students in Shiraz University. Social Sciences

[55] Magazine of Shiraz University. 18(2). pp. 2639.

[56] Grieger, T. A., et al. (2006). "Posttraumatic stress disorder and depression in battleinjured soldiers." American Journal of Psychiatry.

[57] Grinage, B. D. (2003). "Diagnosis and management of posttraumatic stress disorder." American Family Physician 68(12).

[58] Harvey, A. G., et al. (2003). "Sleep and posttraumatic stress disorder: a review." Clinical Psychology Review 23(3): 377407.

[59] Hashemi, Z, MahmoodAliloo M, HashemiNosrat Abad, T.( 2011). The effectiveness of metacognitive therapy on major depression disorder: A case report. J Clin

[60] Psychol. 2(3):8597.

[61] Hassan Zadeh Pashang, S. (2010). Effectiveness of group learning of methods to deal with anxiety, depression and stress in patients suffering from SCl

[62] (Unpublished master's thesis). Tehran: Payame Nour UniversityCentral Branch.

[63] Hopko DR, Hopko SD, Lejuez CW. (2007). Mood Disorders. In Sturmey P (ed) The Handbook of Functional Analysis and Clinical Psychology. New York:

[64] Elsevier Press, 307334.

[65] Ibrahimi, A., Bolhari, J. and Zolfaghari, F. (2000). The difference between various methods of dealing with stress and quality of social support offered to the

[66] wounded in action suffering Spinal Cord Injury indicating severe and mild depression symptoms. Conference Papers on Third Symposium on Nervous

[67] and Mental Problems Resultant from War, (pp. 189199) Tehran: Golban Publications.

[68] James, M, Bolton, A.D, Brian, J, Cox ADC, Bridget, Grant, f, Jitender, S. (2010). Borderline personality disorder and posttraumatic stress disorder: co-occurring

[69] disorders in the U.S.population. J Psychiatric Res.; (44):11901198.

[70] Johnson, S., \& Jacob, T. (2000). Sequential interactions in the martial communication of depressed men and women. Journal of Consulting and Clinical

[71] Psychology, 68,412.

[72] Jones, E., et al. (2003). "Flashbacks and posttraumatic stress disorder: the genesis of a 20thcentury diagnosis." The British Journal of Psychiatry, 182(2):

[73] 158163.

[74] Jordan B K, Marmar C. B , Fairbank J A,Schlenger W. E., Kulka R A ,Hough R L , et al . Problems in families of male Vietnam veterans with posttraumatic stress

[75] disorder. Journal of consulting and clinical psychology .1992; 60:916926.

[76] Kessler, R. C., et al. (2005). Lifetime prevalence and ageofonset distribution of DSMIV disorder in the National Cooccurrence Survey Replication. Archives of

[77] General Psychiatry, 62(6), 593602.

[78] Khaghani Zadeh, M. and Sirati, M. (2004). Impact of economic, social, familyrelated and individual factors on aggravating psychological symptoms in patients

[79] wounded in action. Journal of Military Medicine, 6, pp

[80] Khodaei Ardakani, M.R., and Karami, G.R. (2007). Investigation into psychological disorders' prevalence in patients suffering from nervousmental

[81] problems resultant from war. Tehran: Veterans Medical and Engineering Research Center.

[82] Khodayari, M. and Parand, A. (2006). Stress and different methods to deal with it (3rd Ed.). Tehran: Tehran University Publications.

[83] Krejcie, R.V., \& Morgan, D.W., (1970). Determining Sample Size for Research Activities. Educational and Psychological Measurement, 30. 607610.

[84] Kutz, I., et al. (2008). "The effect of singlesession modified EMDR on acute stress syndromes." Journal of EMDR practice and research 2(3): 190200.

[85] Masaeli, M. and Arfaei, A. (1994). War and peace from the legal and international relations perspective. Tehran: Ministry of Foreign Affairs,

[86] Office for International and Political Studies. 
[87] Maxfield, L. (2003). "Clinical implications and recommendations arising from EMDR research findings." Journal of Trauma Practice 2(1): 6181.

[88] Maxfield, L. (2007). "Current status and future directions for EMDR research." Journal of EMDR practice and research 1(1): 614.

[89] Mirzaei, J. and Hemmati, M.A. (2000). An investigation into congruity of PTSD clinical diagnoses with psychological tests. Conference Papers on Third

[90] Symposium on Nervous and Mental Problems Resultant from War, (pp. 177187) Tehran: Golban Publications.

[91] Mirzaei, J., Karami, G.R., Ameli, J. and Hemmati, M.A. (2004). A comparison between clinical diagnoses of PTSD inpatients and outpatients using psychological

[92] tests. Military Medicine, 6, pp. 201208.

[93] Mohajer, M. (1986). Nowrouz war. Iranian Student Book Agency: Tehran, Shahid Beheshti University, Faculty of Medical Sciences.

[94] Mohammadkhani, P., Stephen Dobson, C., Masah Choulabi, O. (2007). Psychometric properties of the Beck Depression Inventoryll in a large sample of patients

[95] with major depression. Journal of Rehabilitation, 8(29).

[96] Mohsenian, M.B. (2008). Comparison of EQ, mental health and functionality of families' of high school students with parent wounded in action vs. students with

[97] normal parents (Unpublished Master's thesis). Retrieved from Shahid Beheshti University, Tehran .

[98] Moller J, Ahlholm A. (1999). Do episodes of anger trigger myocardial infarction? J Psychosom Med, 61(6), 8429.

[99] Momtazi, S. (2007). Social and cultural factors related to PTSD. A comprehensive theoretical and practical guide to PTSD, pp. 962965 Tehran: Veterans Medical

[100] and Engineering Research Center.

[101] Momtazi, S. (2001). Frequency of depression symptoms in victims of exposure to chemical weapons in Iranlraq War. Abstracts from the 6th Congress on

[102] Psychiatric and Psychological Research. Tehran, Iran.

[103] Moussavi S, Chatterji S, Verdes E, Tandon A, Patel V, Ustun B.( 2007). Depression, chronic disease and decrements in health: Results from the world health

[104] surveys. Lancet. 370 (9590):8518.

[105] NolenHoeksema, S. (2000). "The role of rumination in depressive disorders and mixed anxiety/depressive symptoms." Journal of abnormal psychology 109(3):

[106] 504.

[107] Nouhi, S. (2007). Sleep quality in the wounded in action diagnosed with PTSD. Behavioral Science Journal, 1(2), pp. 7175.

[108] Noorbala, A. (2002). Psychiatric disorders resulting from war in Iran. Journal of Military Medicine, 4(4), p. 2122.

[109] Rosenhan, D., and Seligman M. (1995). Abnormal psychology (Y. Seyyed Mohammadi , Trans). Tehran: Savalan publications.

[110] Roussis P, Wells A.(2006). Posttraumatic stress symptoms: tests of relationship with thought control strategies and beliefs as predicted by the metacognitive

[111] model. Personality and Individual Differences; 40(1): 11122.

[112] Sadock, B. j. and Sadock V.A. (2007). Kaplan and sadock's synopsis of psychology (Rezaei and Farzin, Trans). Tehran: Arjmand Publications.

[113] Saaki, M., Ghanari, A., Masoudi, M. and Kordestani moghaddam, P. (2002). An investigation into mental health of spouses of wounded in action suffering from

[114] spinal cord injury (SCI) in the province of Lorestan in 2001. Conference Papers on Military Health and Hygiene.

[115] Salehi Tali, Sh., Mehralian, H., Imani, R., Khaledi Far, A. and Hatamipour, Kh. (2008). Impact of continuous care and instructive interference on heart patients'

[116] quality of life. Journal of Shahrekord University of Medical Sciences, 10(1), 1419.

[117] Seligman, M. E. P. (1991). Learned optimism: The skill to conquer life's obstacles, large and small. New York: Random House.

[118] Shahraray, M. (2005). Psychological development of the adolescent (1st Ed.). Tehran: Elm Publications.

[119] Shafiei Kamalabadi, M., Bigdeli, I., Alavi, K. and Kian Ersi, F. (2014). Investigation into PTSD prevalence and its cooccurrence with personality disorder in the

[120] wounded in action residing in Tehran. Journal of Clinical Psychology, 6(21), 5677.

[121] Shams, G. (2008). Facing and treating depression (2nd Ed.). Tehran: Roshd Publication.

[122] Shapiro, F. and M. Forrest (2001). "EMDR: Eye movement desensitization and reprocessing." New York: Guilford

[123] Silver, S. M., et al. (2008). "Eye movement desensitization and reprocessing (EMDR) in the treatment of war veterans." Journal of Clinical Psychology 64(8):

[124] 947957.

[125] Sirati Nir M, Ebadi A, Fallahi Khoshknab, M, Tavallaee A. Spiritual Experiences of War Veterans Who Suffer from CombatRelated PostTraumatic Stress 
[126] Disorder:A Qualitative Study. Journal of Religion and Health. 2013;52:71929.

[127] Sotoudeh Asl, N., Asgari MajdAbadi, H. (2004). Mental disorders and mental health in accidents. Abstracts of Second International Conference on Health

[128] Promotion: Treatment and Crisis Management in Case of Accidents. P. 11

[129] Taylor, S. E., et al. (2002). "Toward a biology of social support." In C. R. Snyder \& S. J. Lopez (Eds.), Handbook of positive psychology (pp. 556-569). New York:

[130] Oxford University Press.

[131] Weathers, F W, Litz, B.T.Herman D.S, Huska, J.A \& Keane.T.(1993). The PTSD Checklist (PCL). Reliability. Validity \& diagnostic utility. Presented at the 9 Th

[132] Annual Meeting of the International Society for Traumatic Stress Studies. San Antonio, TX.

[133] Westerink, J., \& Giarratano, L. (1999). The impact of posttraumatic stress disorder on partners and children of Australian Vietnam veterans. Australian \& New

[134] Zealand Journal of Psychiatry, 33, 841-847.

[135] Woods, D. P., Murphy, J. A., Center, K., Russ, C., McLay, R. N., etal. ... Huska, J. A., and Keane, T. M. (1993). The PTSD Checklist (PCL): reliability, validity,

[136] and diagnostic utility. Paper presented at the Annual Meeting of the International Society for Traumatic Stress

[137] Yaghoubi, A. (2011). Diagnosis and treatment of PTSD in the wounded in action. Tehran: Navid Shahed.

[138] Yathrei, K. (2001). Cognitive behavioral therapy efficiency in PTSD patients (Unpublished master's thesis). Retrieved from Tehran Psychiatric Institute, Tehran ..

[139] Zaboli, P., Sanaei, Z., and Bagheri, A. (2001). An investigation into effectiveness of drama therapy (psychodrama) in improving interactive and communication

[140] skills aimed for resolving conflicts between female students and their mothers residing in Tehran. Counseling Research Studies, 4(3).

[141] Zargar F, Forouzandeh E, Mohammadi A, BagherianSararoudi R, Habibi M.(2012). Psychological health of veterans of Iranlraq imposed war: 22 years after the

[142] war. Res Behav Sci. 10(6):54453.

[143] Zarghami, M. (2007). Vulnerability to PTSD . Abstracts from the 4th Symposium on Prevention and Treatment of Psychological Consequences of War (pp. 3444)

[144] Tehran: Research Center for Engineering and Medical Sciences specialized on the Wounded in Action.

[145] Zarrabi H , Najafi K, Shirazi M , Farahi H , Nazifi F, Tadrisi M .The impact of posttraumatic stress disorder on partner of Iranian veterans . Acta medica Iranica. 2008; 46:124128. 